\title{
A INTERNACIONALIZAÇÃO DE EMPRESAS BRASILEIRAS EM UMA PERSPECTIVA MOTIVACIONAL
}

THE INTERNATIONALIZATION OF BRAZILIAN COMPANIES UNDER THE MOTIVATIONAL PERSPECTIVE

\section{LUIZ CARLOS HONÓRIO}

Doutor (PhD) em Administração pela Faculdade de Ciências Econômicas da Universidade Federal de Minas Gerais (Face-UFMG).

Professor titular e pesquisador da Faculdade Novos Horizontes (Unihorizontes). Rua Alvarenga Peixoto, 1270, Santo Agostinho - Belo Horizonte - MG - CEP 30180-121 E-mail: luizhonorio@unihorizontes.br 


\section{RESUMO}

Este artigo discute os resultados de uma pesquisa sobre o comportamento internacional da empresa sob o foco da perspectiva motivacional. Tem por objetivo identificar os tipos de estímulos que impulsionam uma empresa a atuar no exterior e examinar diferenças potenciais relacionadas ao seu comportamento motivacional, com base no tamanho da firma, nas estratégias de entrada e no envolvimento com vendas internacionais. Realizou-se um survey com 73 exportadoras brasileiras do setor de manufatura classificadas no Ministério do Desenvolvimento, Indústria e Comércio Exterior. Os resultados evidenciam que fatores de ordem gerencial e associados aos mercados interno e externo impulsionam as atividades internacionais das empresas pesquisadas e que diferenças significativas se observam entre a maioria desses fatores quanto ao tamanho da firma, à complexidade das estratégias de entrada e ao envolvimento com vendas internacionais.

\section{PALAVRAS-CHAVE}

Internacionalização; Negócios internacionais; Características organizacionais; Motivação internacional; Empreendedorismo internacional.

\section{ABSTRACT}

This current article discusses the results of a research about the international behavior of the firm under the focus of the motivational perspective. The article aims at identifying the types of stimuli that lead a company to operate abroad and at examining the potential differences related to the motivational behavior, based on firm size, strategies of market entry and involvement in international sales. A survey was carried out with 73 Brazilian exporting companies in the manufacturing sector classified in the Ministry of Development, Industry and Foreign Trade. The results show that factors linked to the management and associated with the internal and external markets impel the international activities of the companies 
that were researched; they also show significant differences among the majority of theses factors in relation to size, strategies of market entry and involvement in international sales.

\section{KEYWORDS}

Internationalization; International business; Organizational characteristics; International motivation; International entrepreneurship.

\section{INTRODUÇÃO}

A literatura tem sugerido que os fatores que motivam a internacionalização da empresa podem exercer uma influência sobre os limites das oportunidades internacionais oferecidas (ZAHRA; KORRI; YU, 2004), o movimento de expansão em mercados internacionais (CYRINO; BARCELLOS, 2006) e o processo de formação de uma cultura voltada para a realização de empreendimentos internacionais (SHANE; VENKATARAMAN, 2000). A perspectiva motivacional, representada por esses fatores, evidencia que diferentes estímulos impulsionam uma firma a se internacionalizar (LEONIDOU, I995) e que o papel do empreendedor parece decisivo nas operações internacionais (DIMITRATOS; PLAKOYIANNAKI, 2003).

Estímulos à internacionalização, usualmente, estão associados à exportação e ao investimento direto no estrangeiro (IDE). Este tema, freqüentemente, procura investigar os determinantes individuais, organizacionais e ambientais que configuram o comportamento de exportar (LEONIDOU, I995) e de investir diretamente no exterior (CYRINO; BARCELLOS, 2006). O empreendedorismo internacional, da mesma forma, associa-se a todo e qualquer modo de entrada no mercado estrangeiro, dedicando maior atenção aos determinantes individuais, representados pela figura do empreendedor nas suas ações para identificar e explorar as oportunidades de negócios que surgem no exterior (DIMITRATOS; PLAKOYIANNAKI, 2003).

Estudos sobre gestão internacional também evidenciam que certas características e estratégias da firma - por exemplo, tamanho (GRIPSRUD, I990), modalidades de entrada (TERPSTRA; SARATHY, 2000) e envolvimento com vendas internacionais (KATSIKEAS; PIERCY, I993) - exercem papel importante no comportamento orientado para as atividades internacionais, como também revelam a distribuição e extensão dessas atividades no mercado internacional.

Em face do contexto até aqui delineado, é oportuno buscar uma integração dos temas mencionados anteriormente, de modo a concretizar uma investigação 
mais completa da motivação da firma em prol da realização de negócios internacionais. Tendo em vista essas considerações, este artigo, a partir da utilização de um survey, pretende: a) descrever características e estratégias que evidenciam o comportamento internacional de empresas brasileiras vinculadas ao setor de manufatura; b) identificar os tipos de estímulos que motivam as atividades internacionais das empresas participantes do estudo; e c) examinar diferenças potenciais entre os fatores motivadores da internacionalização das empresas pesquisadas com base no tamanho da firma, nas estratégias de entrada e no envolvimento com vendas internacionais.

O artigo está estruturado em quatro seções. Na primeira, são revisadas as dimensões teóricas que sustentam o estudo realizado: inicialmente, a discussão se volta para os tipos de estímulos classificadores do comportamento internacional motivacional; e, em seguida, são apresentadas as características e estratégias que evidenciam as atividades internacionais da firma. Na segunda, discutem-se os procedimentos metodológicos utilizados na pesquisa. Na terceira, os resultados são revelados e discutidos. Finalmente, na quarta, exibem-se as considerações finais do trabalho.

\section{REVISÃO DE LITERATURA}

\section{ESTÍMULOS À EXPORTAÇÃO E AO INVESTIMENTO DIRETO NO ESTRANGEIRO}

Katsikeas e Piercy (1993) e Leonidou (1995) conceituam estímulos à exportação como os fatores que influenciam a firma a iniciar, desenvolver e manter operações de exportação. Eles são afetados por determinadas forças antecedentes, derivadas de três fontes principais: a) características individuais, b) características organizacionais e c) características ambientais. As características individuais dizem respeito às percepções do tomador de decisões sobre as oportunidades que surgem do mercado internacional. Entre elas, podem ser citadas: características pessoais, orientação internacional, estilo de liderança, competência gerencial e expectativas gerenciais. Quanto às características organizacionais, destacam-se: objetivos corporativos, disponibilidades de recursos, natureza dos produtos e vantagens diferenciais da firma. Finalmente, localização do país, disponibilidade de insumos para a produção, condições econômicas dominantes, facilidades de infra-estrutura e políticas governamentais de apoio à internacionalização configuram-se como características ambientais.

Os estímulos que motivam a exportação podem, ainda, ser subclassificados como internos à firma e externos à firma, argumenta Leonidou (I995). Os estímu- 
los internos à firma estão relacionados às características individuais e organizacionais. São exemplos mais comuns de estímulos internos individuais: existência de interesse ou desejo gerencial em direção à exportação, crenças gerenciais sobre a importância da exportação, experiência gerencial com atividades de exportação e contatos contínuos com gerentes ou outros grupos ocupacionais externos. Cavusgil e Nevin (I98I) sugerem que as aspirações e expectativas gerenciais são determinantes para o comportamento de decisão, atual e futuro, da firma em direção à prática de negócios envolvendo a exportação.

Como exemplos de estímulos internos organizacionais, apontam-se: disponibilidade de capacidade de produção não utilizada, posse de vantagem tecnológica competitiva, acumulação de bens não vendidos/superprodução, potencial de crescimento extra, produção de bens com qualidades singulares, estagnação ou declínio de vendas ou lucros no mercado doméstico, desejo de aumentar a lucratividade da firma, habilidade para modificar facilmente produtos para mercados internacionais e necessidade de reduzir dependência ou risco em relação ao mercado doméstico (LEONIDOU, I995).

Os estímulos externos, por sua vez, associam-se às características do ambiente em que a firma realiza as suas atividades, seja ele doméstico ou internacional. Entre os exemplos de estímulos externos à firma, destacam-se: iniciação de exportação por competidores domésticos, intensificação da competição no mercado doméstico, posse de informações exclusivas sobre mercados internacionais, recebimento de pedidos eventuais do mercado internacional, fornecimento de incentivos ou programas governamentais de apoio à exportação, recebimento de pedidos em missões ou feiras comerciais, regulações favoráveis no mercado-alvo internacional, oportunidade de lucro e crescimento no mercado internacional, movimentos monetários favoráveis, mercados-alvo internacionais mais próximos, entrada de um competidor no mercado doméstico e facilidades de transporte no mercado internacional (LEONIDOU, I995).

Tendo em vista a literatura nacional, observa-se em estudos realizados pela Fundação Dom Cabral (1996) e por Da Rocha (2002) que fatores financeiros, mercadológicos e de natureza diversa estão presentes nas atividades de exportação de empresas brasileiras. Entre os fatores financeiros, aparecem: redução de incidência de impostos, obtenção de incentivos governamentais, obtenção de maiores margens de lucro e diversificação de riscos de câmbio. Quanto aos fatores mercadológicos, revelam-se: penetração em outros mercados, diversificação de clientes, fortalecimento da imagem do produto no mercado doméstico, melhoria da qualidade e eficiência de produtos e serviços, e venda do excedente da produção nacional. Quanto aos fatores de natureza diversa, tanto internos quanto externos à firma, evidenciam-se: aquisição de maior conhecimento gerencial e operacional, facilidades de acesso à tecnologia, possibilidade de fazer parcerias 
(networking), antecipação a futuros competidores e necessidade de aproximação com clientes, distribuidores e fornecedores.

Em consonância com os estudos nacionais evidenciados anteriormente, Ferraz e Ribeiro (2002), investigando o comportamento exportador de pequenas, médias e grandes empresas brasileiras vinculadas ao setor de manufatura, constataram que oportunidade de lucro e crescimento, afinidade/proximidade cultural e menor competitividade de preço em mercados alternativos foram apontados como os principais motivadores daquelas empresas estudadas.

$\mathrm{Na}$ opinião de Cyrino e Barcellos (2006), a exportação é uma das formas mais simples e direta de internacionalização, uma vez que atende apenas a uma dimensão do processo, qual seja, a de estabelecer produtos ou serviços em mercados internacionais. Os autores entendem que, para evoluir no mercado internacional, uma empresa deveria utilizar modalidades de internacionalização de maior comprometimento em termos de ativos (tangíveis e intangíveis) orientados para a conquista e exploração de mercados globais. Certamente, os motivos que impulsionam os negócios internacionais por meio de modalidades de maior comprometimento - por exemplo, o investimento direto no estrangeiro (IDE) devem ser diferentes daqueles associados a modalidades mais simples de envolvimento com o mercado estrangeiro, como é o caso da exportação.

Empresas brasileiras, segundo Cyrino e Barcellos (2006), são motivadas a realizar investimentos diretos no estrangeiro por diversas razões, destacandose a busca de maior controle sobre os canais de distribuição e do contato com o cliente final e a necessidade de estabelecer presença em elos posteriores da cadeia de valor, de modo a responder mais agilmente às demandas locais. Outros motivos destacados pelos autores estão relacionados ao equacionamento de custos associados a atividades de produção, à superação de barreiras tarifárias e nãotarifárias locais, à diversificação de riscos sensíveis a questões de ordem macroeconômica e político-institucional e ao posicionamento competitivo em vários mercados, em resposta à concorrência global. A respeito deste último motivo, os autores citam Dunning (I988) para reiterar que as empresas são impulsionadas a se expandir internacionalmente, sobretudo por motivos econômicos. Esses motivos estão associados à busca: de novos mercados (market seeking), de novas fontes de recursos (resource seeking), de ativos estratégicos (strategic asset seeking) e de eficiência dos mercados globais (efficiency seeking).

Além dos impulsionadores tradicionais de mercado, de custo, de governo e de competição, Cyrino e Barcellos (2006) argumentam que existe um motivo menos observado nas pesquisas sobre a expansão internacional da firma: o grau de intencionalidade relacionado aos esforços empregados pelos dirigentes e pelo corpo gerencial em prol da internacionalização. Para tal, é necessário identificar em que extensão expandir internacionalmente faz parte da agenda estratégica da 
empresa ou de seus valores e crenças. Os esforços nesse sentido podem ser reativos, oriundos de decisões orientadas por pressões inerentes ao mercado doméstico, ou proativos, em que a internacionalização é encarada como uma estratégia intencional de expansão, não importando as condições do mercado de origem.

A literatura sobre empreendedorismo internacional reforça os aspectos gerenciais apontados por Cyrino e Barcellos (2006) como importantes motivadores da expansão internacional da firma. Estudos nesse campo focam especificamente o papel que o empreendedor ocupa nas operações internacionais (DIMITRATOS; PLAKOYIANNAKI, 2003). Na opinião de Dimitratos e Plakoyiannaki (2003), o capital humano empreendedor é uma das forças-chave que a firma possui para obter vantagem das oportunidades que surgem no mercado internacional. Portanto, as percepções, crenças e práticas gerenciais empreendedoras podem estimular a entrada e o desenvolvimento de uma firma no mercado estrangeiro (ZAHRA; KORRI; YU, 2004). Nesse caso, a percepção do empreendedor acerca das possibilidades de realizar atividades exportadoras bem-sucedidas ou de estabelecer parcerias internacionais (uma joint-venture, por exemplo) é um fator individual que pode motivar a internacionalização da firma (OVIATT; McDOUGALL, 2005).

Outro fator individual que pode motivar uma firma a realizar operações internacionais, segundo Katsikeas (I996), refere-se à orientação internacional do empreendedor. Esse tipo de orientação está relacionado a determinadas características pessoais do empreendedor, como o desejo e o entusiasmo em direção ao mercado internacional, as quais geralmente resultam em envolvimento internacional mais alto. Outros fatores motivacionais individuais que podem levar à exploração de oportunidades internacionais relacionam-se ao nível mais alto de educação do empreendedor e ao fato de ele ser de origem estrangeira ou possuir experiência internacional pregressa.

Relatório divulgado pela United Nations Conference on Trade and Development (Unctad) em dezembro de 2004 apontou que um pequeno número de grandes empresas brasileiras havia realizado investimentos no estrangeiro. Algumas motivadas para acessar recursos naturais, outras para evitar barreiras comerciais ou aperfeiçoar infra-estrutura de logística necessária às exportações e outras para seguir ou estar próximas de grandes clientes, de modo a melhor atender às suas necessidades. O relatório da Unctad conclui que até aquele momento as empresas brasileiras tinham sido cuidadosas em seu processo de expansão internacional. Muitas haviam utilizado a estratégia da exportação, e não a do investimento estrangeiro direto, para internacionalizar uma parte de sua produção. Evidências semelhantes foram apontadas anteriormente por Cyrino e Oliveira Jr. (2003) em pesquisa realizada com uma amostra das mil maiores empresas brasileiras, em que apenas $24,2 \%$ delas investiam internacionalmente por meio de, por exemplo, subsidiárias de comercialização ou de produção. 


\subsection{CARACTERÍSTICAS E ESTRATÉGIAS DA FIRMA DETERMINANTES DA INTERNACIONALIZAÇÃO}

Pesquisadores do campo da gestão internacional têm evidenciado o papel que determinadas características organizacionais ocupam no comportamento da firma orientado para o mercado estrangeiro. Entres essas características, sobressaem: o tamanho (GRIPSRUD, I990), as estratégias de entrada (TERPSTRA; SARATHY, 2000) e o envolvimento com vendas internacionais (DIAMANTOPOULOS; INGLIS, I988; KATSIKEAS; PIERCY, I993).

Parece não existir concordância a respeito do impacto que o tamanho pode causar nas atividades internacionais da firma. Estudos realizados por Holzmüller e Kasper (I99I), Wolf e Pett (2000) e Rasheed (2005), por exemplo, evidenciaram que o tamanho da firma provou ter pouca ou nenhuma influência no desempenho corporativo em termos de retorno financeiro advindo das atividades internacionais. Apesar disso, seria razoável sugerir que firmas maiores, comparadas às menores, devem ser mais capazes de perceber uma variedade mais ampla de sinais associados ao mercado internacional e de responder de modo mais positivo a eles. Geralmente, é aceito pela literatura que as firmas maiores possuem mais recursos e mais possibilidades de entrar em mercados mais distantes, os quais podem exigir esforços adicionais (GRIPSRUD, I990).

As estratégias de entrada dizem respeito aos diversos modos que uma firma pode utilizar para atingir adequadamente o mercado internacional. De modo geral, as modalidades de entrada variam em razão do nível de comprometimento de recursos com o mercado internacional e do nível de complexidade exigido na coordenação das operações. Estratégias que envolvem o processo de produção no mercado doméstico implicam níveis mais baixos de comprometimento de recursos e complexidade de operação, como é o caso da exportação. Já as estratégias ligadas à produção no mercado internacional - por exemplo, projetos greenfield - demandam níveis mais acentuados de comprometimento e complexidade (TERPSTRA; SARATHY, 2000). Segundo Welch e Luostarinen (I993) e Li (I995), a escolha do modo de entrada apropriado é um determinante crítico do envolvimento e provável sucesso internacional da firma.

Por fim, o envolvimento com vendas internacionais diz respeito ao desempenho financeiro obtido pela firma em suas operações estrangeiras. O percentual de vendas realizadas no mercado internacional tem sido o indicador mais utilizado para distinguir firmas de maior e de menor envolvimento internacional. Estudo realizado por Diamantopoulos e Inglis (I988) evidenciou que as firmas mais envolvidas com o mercado internacional, ou seja, que apresentavam percentuais de vendas internacionais acima de 50\%, mostravam capacidades internas 
mais desenvolvidas para identificar e explorar oportunidades de exportação. Já o estudo de Katsikeas e Piercy (I993) mostrou que as firmas de menor envolvimento internacional eram motivadas por pressões do mercado doméstico, ao passo que aquelas de maior envolvimento eram mais direcionadas por condições específicas do comércio internacional que estavam além do domínio da firma ou por dimensões associadas a uma política nacional de exportação.

\section{METODOLOGIA}

Esta pesquisa pode ser caracterizada como um levantamento de campo do tipo survey, realizado ex post facto, com caráter descritivo e explicativo. O caráter descritivo justifica-se pela aplicação de um instrumento quantitativo, que tem por finalidade identificar: a) características e estratégias determinantes das atividades internacionais de empresas brasileiras pertencentes ao setor de manufatura; b) principais estímulos que motivam os negócios internacionais das empresas participantes do estudo; e c) diferenças potenciais entre o comportamento internacional motivacional com base nas características e estratégias determinantes dos negócios internacionais das empresas estudadas. O caráter explicativo apóiase na utilização de procedimento estatístico multivariado (análise fatorial), que visa revelar uma estrutura de fatores subjacentes aos principais estímulos motivadores da internacionalização identificados na análise descritiva.

As empresas participantes da pesquisa faziam parte de uma base de dados do Ministério do Desenvolvimento, Indústria e Comércio Exterior, da qual foram selecionadas as setecentas maiores exportadoras brasileiras no ano de 2004 . Esse total foi escolhido intencionalmente, porque era esperado incluir pequenas, médias e grandes empresas que representassem a importância da atividade exportadora para o país e, ao mesmo tempo, realizassem negócios internacionais por intermédio de outras modalidades que não apenas a exportação.

A amostra final ficou constituída de 73 empresas, o que perfaz um percentual de retorno de 10,5\% dos questionários enviados via correio. Como se esperava, a amostra ficou representada por empresas brasileiras de diferentes portes que realizam regularmente negócios internacionais por meio de diversas modalidades, desde a exportação até o investimento direto no exterior. A unidade de observação incluiu presidentes, diretores comerciais, diretores de marketing, diretores de exportação e outros profissionais diretamente envolvidos com operações internacionais. O período de coleta de dados se deu entre os meses de junho e agosto de 2005 .

Utilizou-se na pesquisa um questionário estruturado que se compunha de duas partes: a) características e estratégias determinantes do comportamento internacional da firma e b) motivação internacional. 
A primeira parte englobava questões dispostas em escalas ordinais e dicotômicas que identificavam o tamanho das empresas pesquisadas por número de empregados, as estratégias utilizadas para a execução de operações internacionais e o volume de vendas realizadas no exterior. A segunda parte foi disposta em uma escala de importância com cinco pontos do tipo Likert, composta por estímulos que impulsionam a realização de negócios internacionais. A composição desses estímulos foi inspirada e adaptada da literatura internacional e nacional discutida no artigo. Para fins de validação de forma e conteúdo, o instrumento foi pré-testado e refinado por meio de aplicação em acadêmicos familiarizados com o tema e com executivos envolvidos com negócios internacionais.

Em termos das estatísticas descritivas utilizadas na pesquisa, optou-se pela distribuição de freqüência e medidas de posição média e mediana. As medidas de posição foram empregadas respeitando-se as considerações de Malhotra (200I) de que podem ser usadas em escalas intervalares. Utilizaram-se também medidas de dispersão do tipo intervalo interquartil $\left(\mathrm{P}_{25}\right.$ e $\left.\mathrm{P}_{75}\right)$, uma vez que tais percentis representam bem o posicionamento da unidade amostral.

A análise fatorial empregada no estudo foi realizada de forma exploratória (AFEX) porque se pretendia verificar quais os indicadores motivacionais identificados na análise descritiva poderiam compor uma estrutura de fatores impulsionadores da internacionalização das empresas estudadas. Em seguida, os fatores extraídos foram utilizados em uma aplicação do teste $t$ de Student para descrever se diferenças potenciais poderiam ser observadas entre eles com base no tamanho da firma, nas estratégias de entrada e no envolvimento com vendas internacionais. Esse teste paramétrico mostra-se adequado para pequenas amostras diferentes e fornece inferências para fazer afirmações sobre médias de populações relacionadas.

Para efeito de aplicação do teste $t$, buscou-se dicotomizar as características e estratégias da firma determinantes da internacionalização em amostras independentes (REA; PARKER, 2000), conforme critérios explicitados na seção de discussão dos resultados que trata desse assunto.

\section{APRESENTAÇ̃̃O E DISCUSSÃO DOS RESULTADOS}

\subsection{ANÁLISE DESCRITIVA - CARACTERÍSTICAS E ESTRATÉGIAS DETERMINANTES DA INTERNACIONALIZAÇÃO}

As 73 firmas participantes desta pesquisa foram classificadas por tamanho, estratégias de entrada e envolvimento com vendas internacionais. 
Em termos de tamanho $\mathrm{I}$, a amostra ficou composta por I4 empresas de pequeno porte (I9,20\%), 29 de médio porte $(39,70 \%)$ e 30 de grande porte (4I,I0\%). Esses resultados demonstram certo equilíbrio quanto ao tamanho das empresas pesquisadas, ficando cerca de $60 \%$ classificadas como pequenas e médias, de um lado, e cerca de $40 \%$ como grandes, de outro.

Em termos das estratégias de entrada, constatou-se que 40 das empresas atuantes na pesquisa $(54,50 \%)$ utilizam apenas a exportação, principalmente por meio de intermediários ou unidades próprias localizadas no Brasil. As 33 empresas restantes $(45,50 \%)$ utilizam, além da exportação, estratégias que envolvem contratos de produção, parcerias e, em menor representatividade, aquisições e investimentos greenfield. Tais resultados parecem refletir os argumentos do relatório de 2004 da Unctad e do estudo de Cyrino e Oliveira Jr. (2003), que apontam as empresas brasileiras como cautelosas em seu processo de expansão internacional, optando pela estratégia da exportação, e não a do investimento direto estrangeiro, para internacionalizar uma parte de sua produção.

Quanto ao envolvimento com as operações no mercado estrangeiro, medido pelo percentual de vendas internacionais em relação ao total de vendas, 35 empresas pesquisadas $(48,00 \%)$ afirmaram ser ele de $56 \%$ ou mais; $25(34,20 \%)$, número também significativo considerando o total da amostra, entre $25 \%$ e $55 \%$; e I3 (I7,80\%), até $25 \%$.

\subsection{ANÁLISE DESCRITIVA - ESTÍMULOS IMPULSIONADORES DE NEGÓCIOS INTERNACIONAIS}

Esta parte do instrumento de coleta de dados tinha por objetivo inicial avaliar o grau de importância que os participantes da pesquisa atribuíam a determinados estímulos que impulsionam a realização de negócios internacionais. Tendo em vista que a escala de resposta utilizada para esse fim foi do tipo Likert de cinco pontos, considerou-se como escore médio, ou mediana, o valor 3,o. Uma vez que essa escala era de importância, graduando-se de "nem um pouco importante" a "muito importante", significa dizer que as variáveis que apresentavam escores acima de 3,0 indicavam uma situação de importância e que escores abaixo deste valor indicavam uma situação de pouca ou nenhuma importância. Deve ser ressaltado que os resultados apresentados a seguir são meramente descritivos. Posteriormente, essa escala foi submetida a uma análise fatorial exploratória, para

I Usualmente, a classificação do tamanho de uma empresa pode ser feita com base no número de empregados ou na receita operacional bruta anual. Na pesquisa, optou-se pela primeira modalidade por meio da classificação sugerida pela Fundação Centro de Estudos do Comércio Exterior (Funcex), que estabelece como pequena empresa aquela que tem até ioo empregados; média, de Ioo a 500; e grande, acima de 500 empregados. 
identificar uma estrutura de fatores impulsionadores da internacionalização. Os resultados da análise fatorial serão apresentados e discutidos mais adiante.

Os informantes deram mais importância aos seguintes estímulos: oportunidade de lucro e crescimento no mercado internacional $(4,4)$, necessidade de reduzir a dependência do mercado doméstico $(3,7)$, necessidade de reduzir os riscos em relação ao mercado doméstico $(3,5)$, interesse gerencial em relação a atividades internacionais $(3,5)$, crenças gerenciais sobre a importância da internacionalização $(3,4)$ e intensificação da competição no mercado doméstico $(3,4)$. Com médias um pouco menores, destacaram-se estímulos associados à experiência gerencial internacional e ao processo de produção. Esses resultados podem ser visualizados na Tabela I.

\section{TABELA I}

DISTRIBUIÇA DA AMOSTRA, SEGUNDO OS TIPOS DE ESTÍMULOS IMPULSIONADORES DE NEGÓCIOS INTERNACIONAIS

\begin{tabular}{lcccc}
\hline \multicolumn{1}{c}{ TIPOS DE ESTímULOS } & \multicolumn{3}{c}{ MEDIDA DESCRITIVA } \\
\cline { 2 - 4 } & MÉDIA & $P_{25}$ & MEDIANA & $P_{75}$ \\
\hline $\begin{array}{l}\text { Oportunidade de lucro e crescimento no } \\
\text { mercado internacional }\end{array}$ & 4,44 & 4,0 & 5,0 & 5,0 \\
\hline $\begin{array}{l}\text { Necessidade de reduzir a dependência do } \\
\text { mercado doméstico }\end{array}$ & 3,71 & 3,0 & 4,0 & 5,0 \\
\hline $\begin{array}{l}\text { Necessidade de reduzir os riscos em relação } \\
\text { ao mercado doméstico }\end{array}$ & 3,56 & 3,0 & 4,0 & 5,0 \\
\hline $\begin{array}{l}\text { Interesse gerencial em relação a atividades } \\
\text { internacionais }\end{array}$ & 3,56 & 3,0 & 4,0 & 5,0 \\
\hline $\begin{array}{l}\text { Crenças gerenciais sobre a importância da } \\
\text { internacionalização }\end{array}$ & 3,47 & 2,5 & 4,0 & 5,0 \\
\hline $\begin{array}{l}\text { Intensificação da competição no mercado } \\
\text { doméstico }\end{array}$ & 3,47 & 2,5 & 4,0 & 5,0 \\
\hline $\begin{array}{l}\text { Existência de gerente com experiência } \\
\text { internacional na empresa }\end{array}$ & 2,60 & 1,0 & 2,0 & 4,0 \\
\hline $\begin{array}{l}\text { Habilidade para modificar produtos para o } \\
\text { mercado internacional }\end{array}$ & 2,58 & 1,0 & 2,0 & 4,0 \\
\hline $\begin{array}{l}\text { Produção de bens com qualidades únicas e } \\
\text { singulares }\end{array}$ & 2,56 & 1,0 & 2,0 & 4,0 \\
\hline
\end{tabular}


Os dados da Tabela I antecipam que as empresas brasileiras pesquisadas são mais significativamente motivadas por fatores externos à firma ligados tanto ao mercado exterior quanto ao doméstico. Todavia, os dados também mostram que a orientação da gerência exerce papel importante nas decisões internacionais das empresas estudadas. Os resultados mais significativos encontrados confirmam os estudos de Ferraz e Ribeiro (2002), Unctad (2004) e Cyrino e Barcellos (2006) que apontaram fatores associados ao ambiente internacional em termos de possibilidade de crescimento e lucratividade e ao movimento da concorrência entre os principais motivadores dos negócios internacionais brasileiros.

\subsection{ANÁLISE FATORIAL EXPLORATÓRIA - FATORES MOTIVACIONAIS DOS NEGÓCIOS INTERNACIONAIS}

Antes de apresentar o modelo final da análise fatorial exploratória (AFEX), é pertinente identificar quais foram os indicadores que compuseram a estrutura dos fatores motivacionais da internacionalização retidos para interpretação. A Tabela 2 exibe esses indicadores, os quais foram abreviados pelas iniciais MOT, e a numeração que os acompanha indica a localização das sentenças no questionário aplicado.

\section{TABELA 2}

INDICADORES MOTIVACIONAIS DA INTERNACIONALIZAÇÃO SELECIONADOS NA ANÁLISE FATORIAL

\begin{tabular}{lc}
\hline \multicolumn{1}{c}{ DESCRIÇÃO DOS INDICADORES } & ABREVIATURAS DESIGNADORAS DOS INDICADORES \\
\hline $\begin{array}{l}\text { Necessidade de reduzir a dependência do } \\
\text { mercado doméstico }\end{array}$ & MOT4 \\
\hline $\begin{array}{l}\text { Habilidade para modificar produtos para o } \\
\text { mercado internacional }\end{array}$ & MOT6 \\
\hline $\begin{array}{l}\text { Intensificação da competição no mercado } \\
\text { doméstico }\end{array}$ & MOT8 \\
\hline $\begin{array}{l}\text { Oportunidade de lucro e crescimento no } \\
\text { mercado internacional }\end{array}$ & MOT10 \\
\hline $\begin{array}{l}\text { Interesse gerencial em relação a atividades } \\
\text { internacionais }\end{array}$ & MOT11 \\
\hline $\begin{array}{l}\text { Necessidade de reduzir riscos em relação ao } \\
\text { mercado doméstico }\end{array}$ & \\
\hline
\end{tabular}


TABELA 2 (CONCLUSÃO)

INDICADORES MOTIVACIONAIS DA INTERNACIONALIZAÇAO SELECIONADOS NA ANÁLISE FATORIAL

\begin{tabular}{lc}
\hline \multicolumn{1}{c}{ DESCRIÇÃO DOS INDICADORES } & ABREVIATURAS DESIGNADORAS DOS INDICADORES \\
\hline $\begin{array}{l}\text { Crenças gerenciais sobre a importância da } \\
\text { internacionalização }\end{array}$ & MOT15 \\
\hline $\begin{array}{l}\text { Produção de bens com qualidades únicas } \\
\text { ou singulares }\end{array}$ & MOT17 \\
\hline
\end{tabular}

Fonte: Dados da pesquisa.

Levaram-se em consideração, a priori, dois critérios para a escolha desses indicadores. Primeiro, a opção se deu por indicadores que possuíam cargas fatoriais superiores a .60. A literatura sobre estatística (HAIR JUNIOR et al., I998) aponta que cargas fatoriais no valor de .50 ou acima são consideradas praticamente significantes. Segundo, procurou-se verificar se os indicadores correspondentes ao primeiro critério de escolha agrupavam-se de acordo com as três fontes possíveis de classificação dos estímulos à internacionalização (individual, organizacional e ambiental) sugerida pela literatura.

A Tabela 3 apresenta a matriz de correlações dos indicadores motivacionais selecionados com os respectivos níveis de significância (valor de $p$ ), assinalados em asterisco. A magnitude das correlações que se observa na tabela sugere a nãoexistência de multicolinearidade entre os indicadores da análise.

TABELA 3

MATRIZ DE CORRELAÇÖES DOS INDICADORES MOTIVACIONAIS DA INTERNACIONALIZAÇÃO

\begin{tabular}{|c|c|c|c|c|c|c|c|c|}
\hline INDICADOR & MOT4 & MOT6 & MOT7 & Мот8 & MOT10 & MOT11 & MOT15 & MOT17 \\
\hline Mot4 & - & & & & & & & \\
\hline Mot6 & 0,14 & - & & & & & & \\
\hline Mot7 & $0,33 * * *$ & $0,20 * *$ & - & & & & & \\
\hline Mot8 & $-0,09$ & $0,27 * *$ & 0,04 & - & & & & \\
\hline Mot10 & $-0,05$ & $0,17 *$ & $-0,02$ & 0,11 & - & & & \\
\hline Mot11 & $0,49 * * *$ & $0,27 * *$ & $0,41 * * *$ & 0,04 & $0,30 * * *$ & & & \\
\hline
\end{tabular}




\section{TABELA 3 (CONCLUSÃO)}

MATRIZ DE CORRELAÇÖES DOS INDICADORES

MOTIVACIONAIS DA INTERNACIONALIZAÇÃO

\begin{tabular}{lcccccccc}
\hline INDICADOR & MOT4 & MOT6 & MOT7 & MOT8 & MOT10 & MOT11 & MOT15 & MOT17 \\
\hline Mot 15 & $-0,02$ & $0,18^{*}$ & $-0,04$ & 0,06 & $0,41 * * *$ & 0,18 & - & \\
\hline Mot17 & 0,16 & $0,53 * * *$ & 0,11 & $0,31 * * *$ & $0,23 * *$ & 0,16 & $0,26 * *$ & \\
\hline
\end{tabular}

Fonte: Dados da pesquisa.

$$
* \mathrm{p}<0, \text { IO; **p }<0,05 ; * * * \mathrm{p}<0,0 \text {. }
$$

Verifica-se na Tabela 3 que das 28 correlações calculadas, I2 (42,90\%) apresentaram um nível de significância de $p<0,01$ e $p<0,05$. Esse número de correlações significativas não é considerado alto. Entretanto, outras duas correlações (motio x mot6 e motI5 x mot6) apresentaram valores significativos em um nível de $p<0,10$, elevando o percentual de 42,90\% para 50,00\%, considerado mediano, mas que não inviabiliza a realização da análise fatorial exploratória. Porém, tal fato deve ser encarado como uma limitação da pesquisa.

O método de extração dos fatores se deu pela análise de componentes principais, uma vez que era preocupação do pesquisador identificar o número mínimo de fatores necessários para explicar a maior parte da variância pertinente aos indicadores escolhidos para a análise. Adotou-se o critério da raiz latente para selecionar os fatores motivacionais a serem interpretados. Esse critério estabelece que um fator com autovalor superior a I deve ser retido para análise. Oito fatores apresentaram autovalores acima desse limite, totalizando um percentual acumulado de variância de 7I,56\%. Todavia, apenas os três primeiros fatores foram retidos, porque exibiam cargas fatoriais acima de $0,6 \circ \mathrm{e}$, agrupados, estavam conceitualmente de acordo com as três fontes classificadoras de estímulos à internacionalização (individual, organizacional e ambiental) adotadas pela pesquisa.

Os três fatores retidos para análise respondiam por 40,50\% da variância para a soma média das cargas individuais. Esse valor, apesar de ser considerado baixo pela literatura especializada sobre estatística, era equivalente a mais da metade $(56,30 \%)$ do percentual total da variância acumulada apurada $(71,56 \%)$ pela análise. Entretanto, a mesma literatura sugere que percentuais de explicação abaixo de 60,00\% são considerados aceitáveis, uma vez que as informações no campo das ciências sociais são freqüentemente menos precisas (HAIR JUNIOR et al., I998). 
A medida KMO (Kaiser-Meyer-Olkin) evidenciou um valor acima de o,60, indicando que a amostra era adequada para a matriz de correlação inteira e para cada variável individual avaliada. $\mathrm{O}$ alfa de Cronbach foi superior a o,60 para os três fatores motivacionais extraídos, revelando que a confiabilidade do modelo foi satisfatoriamente alcançada (HAIR JUNIOR et al., I998). A Tabela 4 apresenta o modelo final da AFEX, evidenciando as cargas fatoriais e comunalidades dos indicadores selecionados, os autovalores correspondentes a cada fator extraído, o percentual de explicação da análise e a sua medida de confiabilidade.

TABELA 4

MODELO FINAL DA ANÁLISE FATORIAL PARA OS FATORES MOTIVACIONAIS DA INTERNACIONALIZAÇÃO

\begin{tabular}{|c|c|c|c|c|}
\hline INDICADORES & FATOR 1 & FATOR 2 & FATOR 3 & COMUNALIDADES \\
\hline $\begin{array}{l}\text { Necessidade de reduzir a dependência do } \\
\text { mercado doméstico }\end{array}$ & 0,79 & & & 0,62 \\
\hline $\begin{array}{l}\text { Intensificação da competição no mercado } \\
\text { doméstico }\end{array}$ & 0,62 & & & 0,70 \\
\hline $\begin{array}{l}\text { Necessidade de reduzir os riscos em relação } \\
\text { ao mercado doméstico }\end{array}$ & 0,78 & & & 0,77 \\
\hline $\begin{array}{l}\text { Habilidade para modificar produtos para o } \\
\text { mercado internacional }\end{array}$ & & 0,66 & & 0,63 \\
\hline $\begin{array}{l}\text { Oportunidade de lucro e crescimento no } \\
\text { mercado internacional }\end{array}$ & & 0,73 & & 0,68 \\
\hline $\begin{array}{l}\text { Produção de bens com qualidades únicas ou } \\
\text { singulares }\end{array}$ & & 0,65 & & 0,66 \\
\hline $\begin{array}{l}\text { Interesse gerencial em relação a atividades } \\
\text { internacionais }\end{array}$ & & & 0,82 & 0,67 \\
\hline $\begin{array}{l}\text { Crenças gerenciais sobre a importância da } \\
\text { internacionalização }\end{array}$ & & & 0,72 & 0,76 \\
\hline Autovalores (eigenvalues) & 3,72 & 2,42 & 1,92 & \\
\hline Percentual de explicação da variância & 18,61 & 12,10 & 9,60 & 40,31 \\
\hline Alfa de Cronbach & 0,67 & 0,62 & 0,60 & \\
\hline
\end{tabular}


O fator I conecta estímulos que impulsionam a realização de negócios internacionais relativos ao mercado doméstico em termos de redução de dependência e riscos, e de intensificação da competição. Tais estímulos derivam-se das incertezas do mercado doméstico, geralmente relacionadas à disponibilidade de insumos para a produção e às condições de mercado dominantes, dimensões classificadas por Katsikeas e Piercy (I993) e Leonidou (I995) como ambientais. Esse fator pode ser designado por orientação para o mercado interno.

O fator 2, inversamente, une motivos associados ao mercado estrangeiro ou que são fundamentais aos propósitos de internacionalização da firma - por exemplo: oportunidade de lucro e crescimento no mercado internacional, habilidade para modificar produtos para os clientes internacionais e produção de bens com qualidades únicas ou singulares (KATSIKEAS; PIERCY, I993; LEONIDOU, I995). Por essa razão, é razoável denominar esse fator competitividade dos produtos para o mercado externo.

$\mathrm{O}$ fator 3 capta o interesse gerencial em relação às atividades internacionais e às crenças gerenciais sobre a importância da internacionalização. A literatura tem demonstrado que o capital humano empreendedor é uma das forças-chave para explorar as oportunidades do mercado internacional e que ele se manifesta pelas percepções, crenças e práticas gerenciais empreendedoras (DIMITRATOS; PLAKOYIANNAKI, 2003). Esse fator pode ser nomeado como orientação gerencial.

\subsection{FATORES MOTIVACIONAIS DOS NEGÓCIOS INTERNACIONAIS E AS CARACTERÍSTICAS E ESTRATÉGIAS DETERMINANTES DA INTERNACIONALIZAÇÃO}

Para descrever a existência de diferenças potenciais envolvendo a estrutura dos fatores motivacionais extraída pela análise fatorial em relação ao tamanho da empresa, às estratégias de entrada adotadas e ao envolvimento com vendas internacionais, utilizou-se o teste $t$ de Student para duas amostras independentes relativas às três características mencionadas. Os critérios usados para a definição das amostras independentes são explicitados no parágrafo seguinte. É importante observar que o teste $\mathrm{F}$ foi aplicado, não tendo revelado diferenças significativas de variância, demonstrando que o pressuposto de igualdade de variâncias não foi violado e que os resultados do teste $t$ foram adequados para comparar as amostras independentes de tamanhos diferentes (MALHOTRA, 200I).

A literatura, comumente, classifica como pequena empresa aquela que tem até Ioo empregados; como média, até 500; e como grande, acima de 500. Essa classificação geral foi adotada pela pesquisa, tendo sido dicotomizada como empresas menores, aquelas com 500 empregados ou menos, e como empresas maiores, aquelas que apresentavam acima de $50 \mathrm{I}$ empregados. As estratégias de entrada 
foram dicotomizadas em: estratégias mais simples de entrada (exportação e contratos de produção) e estratégias mais avançadas de entrada (aquisição, parcerias e investimentos diretos do tipo greenfield) (TERPSTRA; SARATHY, 2000). As empresas mais envolvidas foram classificadas como aquelas que manifestavam um percentual de vendas realizadas no mercado internacional de $56,00 \%$ ou mais em relação ao total de vendas, e as empresas menos envolvidas, como aquelas com percentual de 55,00\% ou menos (DIAMANTOPOULOS; INGLIS, I988; KATSIKEAS; PIERCY, I993).

Os resultados do teste mostram a existência de diferenças significativas em um nível de $\mathrm{p}<$.or entre as empresas maiores e as menores quanto ao fator motivacional orientação para o mercado interno. No mesmo nível de significância, verificaram-se diferenças entre as estratégias de entrada quanto ao fator motivacional competitividade dos produtos para o mercado externo. Em um nível de significância $\mathrm{p}<.05$, constataram-se diferenças quanto ao envolvimento com vendas internacionais em relação ao fator motivacional orientação para o mercado interno. Essas evidências são apresentadas na Tabela 5.

\section{TABELA 5}

COMPARAÇÃO DOS FATORES MOTIVACIONAIS BASEADOS NAS CARACTERÍSTICAS E ESTRATÉGIAS DETERMINANTES DA INTERNACIONALIZAÇÃO

\begin{tabular}{lccc}
\hline \multicolumn{1}{c}{$\begin{array}{c}\text { CARACTERISTICAS E } \\
\text { ESTRATÉGIAS DA FIRMA } \\
\begin{array}{c}\text { DETERMINANTES DA } \\
\text { INTERNACIONALIZAÇÃOO }\end{array}\end{array}$} & $\begin{array}{c}\text { ORIENTAÇÃO PARA 0 } \\
\text { MERCADO INTERNO }\end{array}$ & $\begin{array}{c}\text { COMPETITIVIDADE DOS PRODUTOS } \\
\text { PARA O MERCADO EXTERNO }\end{array}$ & $\begin{array}{c}\text { ORIENTAÇÃO } \\
\text { GERENCIAL }\end{array}$ \\
\hline Empresas menores & $-0,26$ & $-0,05$ & 0,18 \\
\hline Empresas maiores & 0,41 & 0,09 & $-0,20$ \\
\hline $\begin{array}{l}\text { Valor de } t \\
\text { Estratégias simples de } \\
\text { entrada }\end{array}$ & $-2,84 * * *$ & $-0,06$ & 1,61 \\
\hline $\begin{array}{l}\text { Estratégias avançadas } \\
\text { de entrada }\end{array}$ & 0,37 & $-0,17$ & 0,18 \\
\hline $\begin{array}{l}\text { Valor de } t \\
\text { Empresas menos } \\
\text { envolvidas }\end{array}$ & $1,71 *$ & 0,59 & 0,16 \\
\hline
\end{tabular}


TABELA 5 (CONCLUSÃO)

COMPARAÇA DOS FATORES MOTIVACIONAIS BASEADOS NAS CARACTERÍSTICAS E ESTRATÉGIAS DETERMINANTES DA INTERNACIONALIZAÇÃO

\begin{tabular}{lccc}
\hline \multirow{2}{*}{$\begin{array}{c}\text { CARACTERISTICAS E } \\
\text { ESTRATÉGIAS DA FIRMA } \\
\text { DETERMINANTES DA }\end{array}$} & FATORES MOTIVACIONAIS & \\
\cline { 2 - 4 } INTERNACIONALIZAÇÃOO & $\begin{array}{r}\text { ORIENTAÇÃO PARA O } \\
\text { MERCADO INTERNO }\end{array}$ & $\begin{array}{c}\text { COMPETITIVIDADE DOS PRODUTOS } \\
\text { PARA O MERCADO EXTERNO }\end{array}$ & $\begin{array}{c}\text { ORIENTAÇÃO } \\
\text { GERENCIAL }\end{array}$ \\
\hline $\begin{array}{l}\text { Empresas mais } \\
\text { envolvidas }\end{array}$ & $-0,31$ & 0,22 & 0,19 \\
\hline Valor de $t$ & $2,54^{* *}$ & $-1,79 *$ & $-1,35$ \\
\hline
\end{tabular}

Fonte: Dados da pesquisa.

Empresas menores $=500$ empregados ou menos $(n=43)$.

Empresas maiores $=501$ empregados ou mais $(n=30)$.

Estratégias simples de entrada = exportação e contratos de produção $\left(n={ }_{5}^{6}\right)$.

Estratégias avançadas de entrada = parcerias, aquisição e investimentos diretos do tipo greenfield $(\mathrm{n}=\mathrm{I} 7)$.

Empresas menos envolvidas $=55,00 \%$ ou menos de vendas internacionais $(\mathrm{n}=38)$.

Empresas mais envolvidas $=56,00 \%$ ou mais de vendas internacionais $(n=35)$.

$* * *$ significância $\mathrm{p}<0$, OI.

** significância $\mathrm{p}<0,05$.

* significância $\mathrm{p}<0$,IO.

Mais especificamente, os resultados da Tabela 5 mostram que as empresas maiores (média $=0,4 \mathrm{I}$ ) são significativamente mais propensas a realizar negócios internacionais, estimuladas por fatores motivacionais associados ao mercado interno $(t=-2,84 \mathrm{em} \mathrm{p}<0, \mathrm{OI})$, quando comparadas com as empresas menores (média $=-0,26$ ). As empresas da amostra, visivelmente voltadas para os sinais do mercado doméstico, parecem encarar a internacionalização como algo decorrente de pressões internas, e não como uma perspectiva de expansão para além das fronteiras nacionais.

A literatura evidencia que as firmas maiores, em comparação com as menores, mostram-se mais estimuladas pelos sinais do mercado internacional, uma vez que possuem os recursos necessários para responder mais positivamente a eles (GRIPSRUD, I990). Os resultados exibidos na Tabela 5 não reforçaram essa evidência, entretanto é possível perceber pelas argumentações de Cyrino e Barcellos (2006) que grandes empresas brasileiras são estimuladas a realizar negócios internacionais por diversas razões, tanto associadas ao mercado de origem 
quanto ao mercado internacional. Pressupõe-se que os esforços gerenciais das empresas maiores participantes da pesquisa em prol dos negócios internacionais parecem se mostrar reativos, segundo a classificação desses autores, uma vez que as razões que impulsionam os negócios internacionais do grupo de empresas pesquisado foram motivadas por aspectos particulares do mercado brasileiro por exemplo, associados à redução de dependência/riscos e à intensificação da competição.

Em relação à entrada no mercado internacional, os resultados do teste sugerem que as empresas que utilizam estratégias mais avançadas (média $=0,59$ ) são mais motivadas pelo fator associado à competitividade dos produtos para o mercado externo $(t=2,80$ em $\mathrm{p}<0, \mathrm{OI})$, quando comparadas com as empresas que utilizam estratégias mais simples (média $=-0, \mathrm{I}$ ) . Esse fator inclui motivos particulares ao mercado estrangeiro ou que são fundamentais aos propósitos de internacionalização, por exemplo, relacionados ao processo produtivo da firma. Essas evidências convergem com os dados recentes do relatório da Unctad publicado em dezembro de 2004, que reconhece a existência de algumas empresas brasileiras que investem diretamente no estrangeiro, procurando equacionar questões específicas do mercado internacional associadas, por exemplo, ao acesso a recursos naturais, ao aperfeiçoamento de infra-estrutura logística ou à necessidade de se aproximar da clientela.

Os resultados discutidos no último parágrafo também convergem com as argumentações de Cyrino e Barcellos (2006), quando observam que os motivos impulsionadores de investimentos diretos de empresas brasileiras no estrangeiro estão mais associados a sinais do mercado internacional - por exemplo, necessidade de: buscar maior controle sobre os canais de distribuição e contato com o cliente final; estabelecer presença em elos posteriores da cadeia de valor, de modo a responder mais agilmente às demandas locais; superar barreiras tarifárias e não-tarifárias locais; e posicionar-se de forma competitiva em vários mercados em resposta à concorrência global. Esses motivos parecem reforçar o posicionamento de Welch e Luostarinen (1993) e Li (I995), quando argumentam que modalidades mais avançadas de entrada implicam maior envolvimento e maior probabilidade de ações bem-sucedidas no mercado internacional.

Esperava-se que o fator motivacional de ordem gerencial exibisse um relacionamento significativo com as estratégias de entrada, o que de fato não ocorreu. Estudos realizados por Katsikeas (I996), Oviatt e McDougall (2005) e Cyrino e Barcellos (2006) mostram que os interesses e as crenças gerenciais exercem papel relevante no envolvimento e comprometimento da firma quanto ao desenvolvimento de suas atividades de internacionalização. De qualquer forma, seria necessário realizar uma investigação em profundidade com as empresas envolvidas no estudo para, além de quaisquer pressuposições teóricas, levantar possí- 
veis razões que expliquem a inexistência de associação entre as dimensões não evidenciadoras de resultados significativos.

Finalmente, os resultados da Tabela 5 demonstram que as empresas mais envolvidas com vendas internacionais (média $=-0,3 \mathrm{I}$ ) são mais motivadas por fatores ligados ao mercado interno $(t=2,54 \mathrm{em} \mathrm{p}<0,05)$, quando comparadas com as empresas menos envolvidas (média $=0,28$ ), no que se refere, por exemplo, a questões associadas à redução da dependência e dos riscos relativos ao mercado doméstico e à intensificação da competição. Esse resultado não reforça o estudo de Katsikeas e Piercy (I993), o qual aponta que as empresas de maior envolvimento são mais direcionadas por condições específicas do mercado internacional ou por dimensões pertencentes a uma política nacional de exportação. Sugere-se que o último aspecto ainda não se apresenta consistente e ou estável do ponto de vista da estruturação do ambiente econômico-institucional brasileiro em prol do incentivo e do apoio à internacionalização de suas empresas.

\section{CONSIDERAÇÕES FINAIS}

Este artigo revelou três evidências importantes. A primeira identificou que a maior parte das empresas brasileiras de manufatura pesquisadas, apesar de demonstrar envolvimento com vendas internacionais, utiliza estratégias de entrada consideradas de menor complexidade e comprometimento de recursos. Isso sugere um baixo grau de internacionalização, uma vez constatada a não-opção por investimentos diretos no estrangeiro, conforme mostram estudos anteriores envolvendo a realidade brasileira.

Em relação à segunda evidência, os resultados encontrados revelaram que as empresas brasileiras pesquisadas são mais significativamente motivadas a realizar negócios internacionais, pela oportunidade de obter lucro e crescimento com as atividades no exterior, pela necessidade de reduzir a dependência e os riscos em relação ao mercado doméstico e pela intensificação da competição no mercado doméstico. Constatou-se que aspectos gerenciais do ponto de vista dos interesses e das crenças, em face das atividades internacionais, também exercem um papel importante na motivação em favor das atividades internacionais.

Quanto à terceira evidência, constatou-se a existência de diferenças potenciais significativas entre parte da estrutura de fatores motivacionais, revelada pela análise fatorial aplicada na pesquisa, e o tamanho da firma, os modos de entrada utilizados e o envolvimento com vendas internacionais.

As empresas maiores participantes da pesquisa tendem a se impulsionar internacionalmente por motivos específicos do mercado doméstico. Esse resultado sugere que essa categoria de empresas estudadas percebe mais fortemente a 
internacionalização como algo reativo a pressões internas, e não como uma perspectiva de expansão para além das fronteiras nacionais. As empresas que utilizam modos mais avançados são motivadas por fatores particulares do mercado internacional, fato que se alinha com estudos precedentes, que identificaram algumas empresas brasileiras investindo diretamente no estrangeiro, buscando equacionar questões específicas do mercado internacional - por exemplo, acesso à matériaprima, aperfeiçoamento de infra-estrutura logística, necessidade de se aproximar da clientela, superação de barreiras tarifárias e não-tarifárias, e posicionamento em vários mercados para responder aos concorrentes globais. Inversamente, fatores ligados ao mercado doméstico impulsionam as empresas mais envolvidas com vendas internacionais, contrariando evidências anteriores. Fatores de ordem gerencial, apesar de exercerem um papel importante na motivação internacional das empresas estudadas, não exibiram um relacionamento significativo com as características e estratégias da firma determinantes dos negócios internacionais.

Por fim, é oportuno ressaltar algumas limitações do estudo. Primeira, a análise ex post facto, apesar de ser largamente utilizada em pesquisas sobre negócios internacionais, pode apresentar vieses difíceis de serem equacionados, por exemplo, aqueles que poderiam resultar da investigação dos motivos subjacentes às decisões internacionais de uma firma que atua há muitos anos no mercado estrangeiro. Segunda, o tamanho da amostra final, apesar de atender às exigências de aplicação das técnicas estatísticas utilizadas, não proporciona bases suficientes para fazer generalizações. Terceira, instrumentos de pesquisa que utilizam fontes primárias de levantamento de dados são suscetíveis a julgamentos pessoais, que podem introduzir erros significativos na medição dos resultados, não obstante o instrumento de coleta dos dados ter sido pré-testado com acadêmicos e executivos diretamente envolvidos com negócios internacionais. Além disso, a abordagem quantitativa não exaure as complexidades envolvidas em estudos sobre negócios internacionais, devendo-se utilizar abordagens qualitativas para fins de aprofundamento dos dados.

\section{REFERÊNCIAS}

CAVUSGIL, S. T.; NEVIN, J. R. Internal determinants of export marketing behavior: an empirical investigation. Journal of Marketing Research, v. I8, n. I, p. II4-II9, I98I.

CYRINO, Á. B.; BARCELLOS, É. P. Estratégias de internacionalização: evidências e reflexões sobre empresas brasileiras. In: TANURE, B.; DUARTE, R. G. (Org.). Gestão internacional. São Paulo: Saraiva, 2006.

CYRINO, Á. B.; OLIVEIRA JR., M. M. Emerging global players: evidences from the internationalization process of Brazilian firms. In: ENCONTRO NACIONAL DE PÓS-GRADUAÇÃO E PESQUISA EM ADMINISTRAÇÃO, 27., 2003, Atibaia. Anais... Atibaia: Enanpad, 2003. 
DA ROCHA, A. Internacionalização das empresas brasileiras. Rio de Janeiro: Mauad, 2002. DIAMANTOPOULOS, A.; INGLIS, K. Identifying differences between high and low-involvement exporters. International Marketing Review, v. 5, n. 2, p. 52-60, I988.

DIMITRATOS, P.; PLAKOYIANNAKI, E. Theoretical foundations of an international entrepreneurial culture. Journal of International Entrepreneurship, v. I, p. I87-215, 2003.

DUNNING, J. H. The theory of international production. The International Trade Journal, v. 3, n. I, p. 2I-66, I988.

FERRAZ, G. T.; RIBEIRO, F. J. Um levantamento de atividades relacionadas às exportações das empresas brasileiras: resultados de pesquisa de campo com 460 empresas brasileiras. In: BNDES. O desafio das exportações. Rio de Janeiro: BNDES, 2002.

FUNDAÇÃO DOM CABRAL. Internacionalização de empresas brasileiras. Rio de Janeiro: Qualitymark, I996.

GRIPSRUD, G. The determinants of export decisions and attitudes to a distant market: Norwegian fishery exports to Japan. Journal of International Business Studies, v. 2I, n. 3, p. 469-485, I990. HAIR JUNIOR, J. F. et al. Multivariate data analysis. New Jersey: Prentice Hall, I998.

HOLZMÜLLER, H. H.; KASPER, H. Personal and organizational determinants of export trade activities observed in small and medium-sized firms. Management International Review, v. 3I, p. 45-70, I99I.

KATSIKEAS, C. S. Ongoing export stimulation: differences between regular and sporadic exporters. International Marketing Review, v. I3, n. 2, p. 4-19, 1996.

KATSIKEAS, C. S.; PIERCY, N. F. Long-term export stimuli and firm characteristics in a European LDC. Journal of International Marketing, v. I, n. 3, p. 23-47, I993.

LEONIDOU, L. C. Export stimulation research: review, evaluation and integration. International Business Review, v. 4, n. 2, p. 133-156, 1995.

LI, J. Foreign entry and survival: effects of strategic choices on performance in international markets. Strategic Management Journal, v. I6, n. 5, p. 333-35I, I995.

MALHOTRA, N. K. Pesquisa de marketing: uma orientação aplicada. Porto Alegre: Bookman, 2OOI.

OVIATT, B. M.; McDOUGALL, P. P. Defining international entrepreneurship and modeling the speed of internationalization. Entrepreneurship: Theory \& Practice, v. 29, n. 5, p. 537-553, Sept. 2005.

RASHEED, H. S. Foreign entry mode and performance: the moderating effects of environment. Journal of Small Business Management, v. 43, n. I, p. 4I-54, 2005.

REA, L. M.; PARKER, R. A. Metodologia de pesquisa: do planejamento à execução. São Paulo: Pioneira, 2000.

SHANE, S.; VENKATARAMAN, S. The promise of entrepreneurship as a field of research. Academy of Management Review, v. 25, n. I, p. 217-226, 2000.

TERPSTRA, V.; SARATHY, R. International Marketing. USA: Thomson Learning, 2000.

UNCTAD. United Nations Conference on Trade and Development. Unctad Ocassional Note. Outward FDI from Brazil: poised take off? New York, Geneva: Unctad, Dec. 2004.

WELCH, L. S.; LUOSTARINEN, R. K. Internationalization: evolution of a concept. In: BUCKLEY, P. J.; GHAURI, P. N. (Ed.). The internationalization of the firm: a reader. London: Academic Press, I993. 
- A INTERNACIONALIZAÇÃO DE EMPRESAS BRASILEIRAS EM UMA PERSPECTIVA MOTIVACIONAL • LUIZ CARLOS HONÓRIO

WOLF, J. A.; PETT, T. L. Internationalization of small firms: an examination of export competitive patterns, firm size, and export performance. Journal of Small Business Management, v. 38, p. 34-47, 2000.

ZAHRA, S. A.; GEORGE, G. International entrepreneurship: the current status of the field and future research agenda. In: HITT, M. A. et al. (Ed.). Strategic entrepreneurship: creating an integrated mindset. Oxford: Blackwell, 2002.

ZAHRA, S. A.; KORRI, J. S.; YU, J. Cognition and entrepreneurship: implications for research on international opportunity recognition and exploitation. International Business Review, v. XX, p. I-I8, 2004 .

TRAMITAÇ ÃO

Recebido em 4/7/2007

Aprovado em 13/9/2007 